九州大学学術情報リポジトリ

Kyushu University Institutional Repository

The Development of a Small Group of Momi (Abies firma) and Tsuga (Tsuga sieboldii) on the Basis of Diameter and Height Growth

Yuruki, Tatsuro

University Forests, Faculty of Agriculture, Kyushu University

Aragami, Kazutoshi

University Forests, Faculty of Agriculture, Kyushu University

Marutani, Tomomi

University Forests, Faculty of Agriculture, Kyushu University

https://doi.org/10.5109/23861

出版情報 : 九州大学大学院農学研究院紀要. 31 (4)，pp.411-415，1987-03-31. Kyushu University バージョン：

権利関係 : 


\title{
The Development of a Small Group of Momi (Abies firma) and Tsuga (Tsuga sieboldii) on the Basis of Diameter and Height Growth
}

\author{
Tatsuro Yuruki, Kazutoshi Aragami and Tomomi Marutani \\ University Forest, Faculty of Agriculture, \\ Kyushu University, Fukuoka 812 \\ (Received December 10,1986)
}

\begin{abstract}
The development of a small group of Momi (Abies firma) and Tsuga (Tsuga sieboldii) was elucidated from a viewpoint of the individual growth. The differences in growth between individuals were obviously caused by the differences in the time of their occurrences in the gap and it appeared that the group had been separated into two height classes and three diameter classes around 30-40 years after occurrences, It is remarkable that a tree ranked into a superior class with regard to height and a medium class with regard to diameter has an elliptical crown. The fluctuation of individual rankings in a small group of Momi and Tsuga trees is similar to that in a large group. It is possible to estimate the growth process of a group, especially the time of layering, according to the fluctuation of individual rankings.
\end{abstract}

\section{INTRODUCTION}

Up to the present time, the growth of a natural community has been mainly studied from the viewpoint of biomass. On the other hand, it has to be admitted that large differences in growth can come about between individuals with the development of a community. Accordingly, it is considered necessary to elucidate the development of a community from a viewpoint of the growth of an individual. It is known that the rankings of individuals in a community change with the progress of growth (Tadaki and Shidei, 1962; Tamai, 1980; Tamai et al., 1983). We have therefore tried to elucidate the development of a Momi and Tsuga community from the viewpoint of fluctuation of an individual ranking with regard to diameter and observed that it was possible to separate Momi and Tsuga trees into three ranking classes (Yuruki and Aragami, 1986).

In general, Momi and Tsuga forests are recognized to be complexes of certain groups (Nakao, 1985). In the present paper, we tried to elucidate the formation of a small group of Momi and Tsuga in terms of changes in individual rankings of height as well as diameter.

\section{MATERIALS AND METHODS}

The investigated forest was a small area of Momi and Tsuga natural forest in compartment 34 of Kyushu University Forest in Miyazaki (latitude: 34" 23' N, lon- 
gitude : 131" 10 ' E, altitude : $1000 \mathrm{~m}$, warmth index : 85, topography : middle part of south slope, inclination of slope : 5 "). The area of forest contained a small group of 7 Momi and 2 Tsuga individuals. Stem analysis at 1-m intervals was carried out on all individuals, the growth in diameter at the cutting height was measured with an accuracy of $1 / 10 \mathrm{~mm}$ and height growth was estimated from the results of stem analysis. Each individual ranking was determined according to the diameter or height at a certain time.

\section{RESULTS AND DISCUSSION}

The investigated small group of Momi and Tsuga trees had a large difference between individuals and four individuals were oppressed completely by the other individuals as shown in Fig. 1. The ages of individuals ranged from 81 to 92 years, as shown in Table 1, a difference of 11 years existing between the oldest and youngest individuals in the group. Nakao (1985) presumed that Momi and Tsuga populations were a complex of certain groups, each having a contagious age structure, and that the formation of the group was related to gaps in the forest canopy. Suzuki (1980) reported that Tsuga saplings which had germinated on a dark forest floor in a stabilized stand seemed to survive for 20 years, but that they grew rapidly after their release due to gap formation. We also reported that the life spans of Momi and Tsuga saplings under competition from higher trees were very short (Yuruki and Aragami, 1973). Judging from the age structure, it was considered that this small group of Momi and Tsuga trees had developed in a small gap. As weeds and shrubs usually grow thickly in gaps,
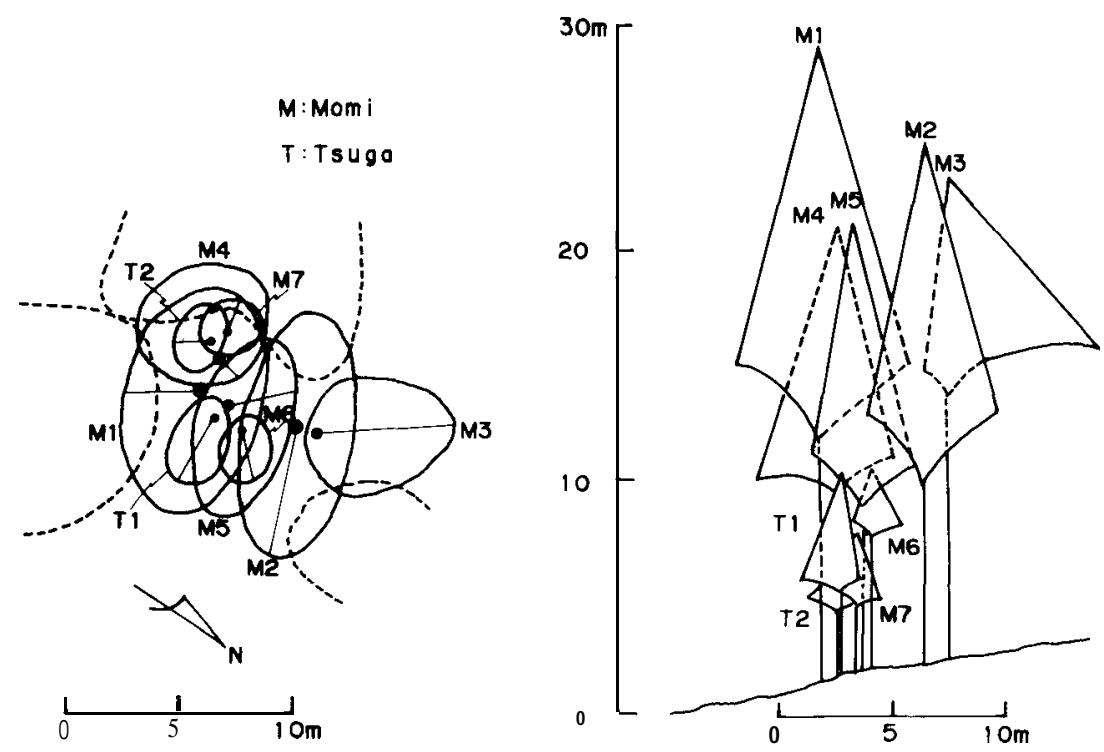

Fig. 1. Crown projection and profile of the investigated Momi and Tsuga group 
Table 1. Surveyed trees.

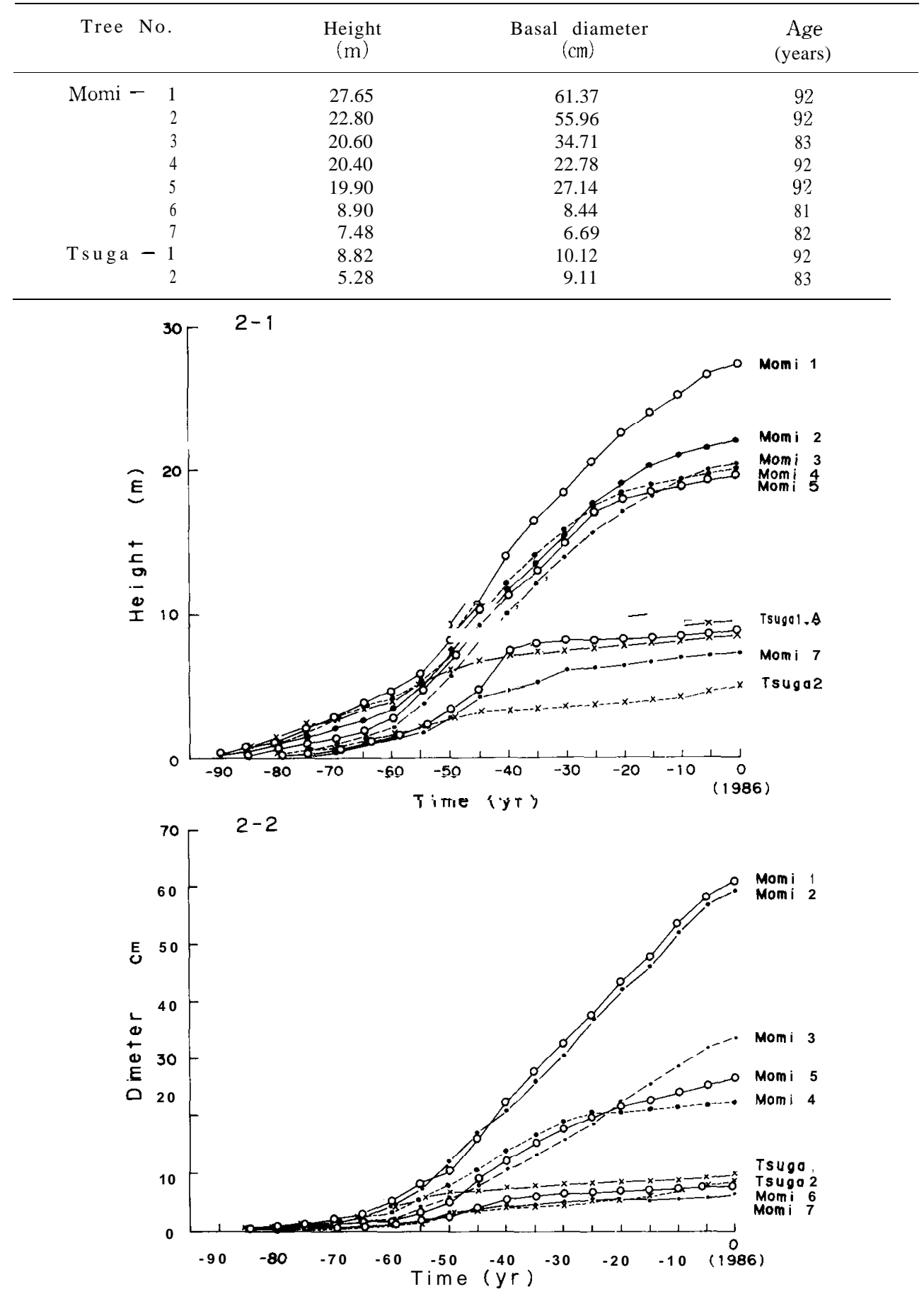

Fig. 2. Growth curves. Height growth $(2-1)$ and diameter growth (2-2). 
it would seem to be difficult to judge whether Momi and Tsuga saplings would germinate and grow normally following gap formation. Accordingly, it was considered that Momi and Tsuga trees had germinated before gap formation. Considering these conditions, it was assumed that this gap had been formed after 80 years.

Fig. 2 shows the growth curve of each individual. It appeared that the group had been separated into two height classes and three diameter classes 40 years previously. The differences in growth between individuals were obviously caused by the differences in their times of occurrence in the group. Three individuals (Momi No. 3, No. 4 and No. 5) in the group were ranked into a medium class with regard to diameter and a superior class with regard to height. All these individuals had elliptical crowns (Fig. 1). It is assumed that the formation of elliptical crown is due to the unequal oppression by adjacent trees. It is known that the influence of competitive interaction between individuals is expressed initially in the form of diameter growth (Tadaki and Shidei, 1964). Obviously, in these three individuals with elliptical crowns, the effect of competitive interaction is expressed on a diameter growth to a greater extent than height growth. Judging from these results, it can be considered that an individual ranked into a superior class with regard to height and a medium class with regard to diameter has an elliptical crown and would be in an unstable position within the group comparatively. It was remarkable that Momi No. 3 occurred latest in the group was ranked into a superior class with regard to height. This phenomenon shows that, with regard to height, an individual occurred later under suppressed condition is able to out-do an individual occurred earlier when it develops an elliptical crown.

We reported that it was possible to separate a large group of Momi and Tsuga trees into three diameter classes- a superior, a medium and a subordinate class with regard to diameter, according to the fluctuation of individual ranking (Yuruki and Aragami, 1986). Fig. 3 shows the fluctuation of individual rankings in diameter and height with the progress of individual growth. We can read the growth process of group in this figure. The rankings in diameter and height fluctuate appreciably during the 40 to 50 years following occurrence and then become stable in the same way as the

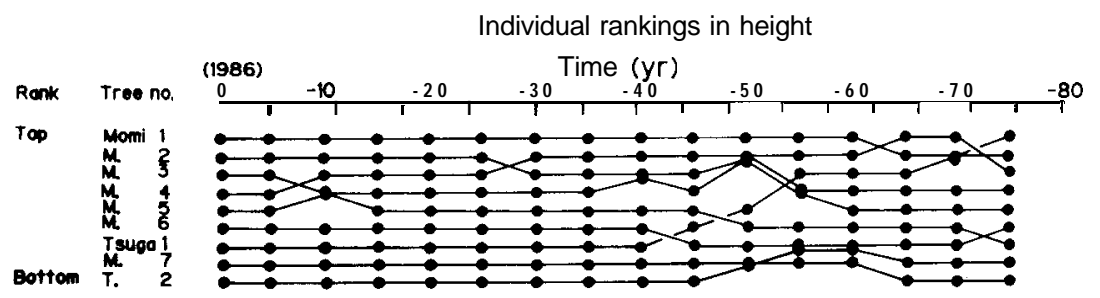

Individual rankings in diameter
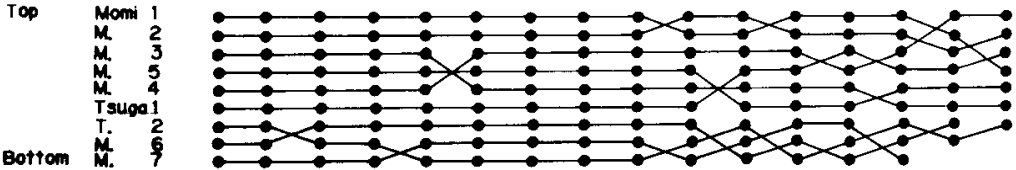

Fig. 3. Fluctuation of individual rankings in diameter and height. 
growth curves (Fig. 2). Obviously, the fluctuation of individual ranking in this small group is in agreement with that in a large group (Yuruki and Aragami, 1986). This phenomenon shows that it is possible to estimate the growth process of a Momi and Tsuga forests, especially the time of layering, according to fluctuations of individual rankings.

\section{REFERENCES}

Nakao, T. 1985 Ecological studies of Abies and Tsuga Forests in Kyushu, Japan. Bull. Miyazaki Univ. For., 11: 1-165 (in Japanese with English summary)

Suzuki, E. 1980 Regeneration of Tsuga sieboldii forest II. Two cases of regenerations occurred about 260 and 50 years ago. Jap.J. Ecol., 30:333-346 (in Japanese with English summary)

Tadaki, Y. and T. Shidei 1962 Studies on competition of forest trees (IV). The order-fluctuation of individuals in stand with progress of growth. J.Jpn. For. Soc., $44: 203-212$ (in Japanese with English summary)

Tadaki, Y. and T. Shidei 1964 The ecological studies on the quantitative thinning. Bull. Kyoto Univ. For, 34: 1-31 (in Japanese with English summary)

Tamai, S. 1980 Density effects on the growth of trees at early growing stage in alder (Alnushirsuta var. sibirica) stand. Bull. Kyoto Univ. For., 52:22-31

Tamai, S., Y. Ohkubo and T. Tsutsumi 1983 Studies on the effects of thinning small-diameter trees (VI). Changes in structure and biomass of a Cryptomeria japonica stand during the twelve years after thinning. J.Jpn. For. Soc., 65: 372-381 (in Japanese with English summary)

Yuruki, T. and K. Aragami 1973 Studies on natural regeneration of Momi (Abies firma S. et Z., Japanese fir) and Tsuga (Tsuga sieboldii Carr., Japanese hemlock). Bull. Kyushu Univ. For., 47: 77-124 (in Japanese with English summary)

Yuruki, T. and K. Aragami 1986 The development of Momi and Tsuga forest on the basis of diameter growth. J.Jpn. For. Soc. (in contribution) 